\title{
Gangrene Associated with Human Immunodeficiency Virus (HIV)
}

\author{
Malladi VSS1, Abkari S 2 and Srinivasan VR ${ }^{1}$ \\ ${ }^{1}$ Nizam's Institute of Medical Sciences, Hyderabad, \\ ${ }^{2}$ Aware Global Hospital, Hyderabad, \\ India
}

\section{Introduction}

The common aetiologies of gangrene of the extremities are atherosclerosis and diabetes mellitus. An internist may encounter several other diseases which can cause gangrene of extremities. Systemic lupus erythematosus, progressive systemic sclerosis, HenochSchonlein purpura, anti-neutrophil cytoplasmic antibody (ANCA) associated vasculitis, Takayasu arteriitis, infective endocarditis, gangrene associated with procoagulant states due to malignancy, anticardiolipin antibody syndrome and disseminated intravascular coagulation are some of the important causes of gangrene of the extremities. Rare causes of gangrene include heparin induced thrombocytopenia (HIT), haemolytic uremic syndrome (HUS) and Human immunodeficiency virus (HIV) infection.

HIV infection involves all the systems of the body, and the cardiovascular system is no exception. HIV vasculopathy was first described as an entity in 1987 (Joshi et al., 1987). HIV associated vasculopathy may present with arterial occlusive disease, aneurysmal disease, aortic dissection or spontaneous arteriovenous fistula (Mulaudzi, 2005; Nair, 1999, 2000, 2001; Pantula, 2009). Vasculitis is one of the less common but important consequences of HIV (Chetty, 2001). Aneursymal disease is thought to be due to vasculitis of vasa vasorum leading to inflammation with resultant transmural fibrosis or necrosis and the formation of true or false aneurysms (Mulauldzi et al., 2005). HIV-related thrombosis, which is segmental, shows a histological picture identical to that seen in aneurysms, with inflammatory changes confined to the vasa vasora with bland organising luminal thrombosis. This strongly suggests that aneurysm and thrombosis are different expressions of the same pathological process.

Peripheral arterial disease (PAD) is more prevalent in the HIV-infected population than in the general population (Periard, 2008). There is a six-fold increased risk for PAD in HIVinfected individuals as well as an earlier onset of the disease compared with HIV-negative patients (Periard et al., 2008). Broad spectrum of rheumatic syndromes are associated with HIV infection ranging from arthralgias to reactive arthritis, myopathy and fibromyalgia to more severe necrotizing vasculitis (Uppal \& Achutan, 1997). Almost every pattern and type of vasculitis of small, medium and large vessels has been encountered in the HIV setting (Chetty, 2001). Widespread digital ischemic changes and gangrene of the hands and feet is an uncommon presentation in patients with HIV infection (Roh \& Gertner, 1997). There are several reports on HIV associated occlusive vasculopathy from Africa. Reports from India on this subject are limited. 


\section{Materials and methods}

Data of 1311 HIV reactive patients was obtained retrospectively from the medical records of department of medicine from the year 2000 to 2010. All HIV positive patients' records were studied. Records of patients with gangrene were identified and studied.

HIV testing was done by HIV Vironostika (4th Generation ELISA, BioMerieux, France). All HIV reactive samples were then tested by HIV TRIDOT (J Mitra, India), a rapid assay that allows differentiation between HIV 1 and 2. The reactive samples were further confirmed by a Western Blot assay (HIV Blot 2.2, Gene labs Diagnostics, USA). CD4 counts were determined by using the FACS Count (Becton Dickinson, USA). HIV Viral loads were estimated by the AMPLICOR assay (Roche, USA).

\section{Our experience}

In our experience over the last 10 years in a south Indian tertiary care hospital we have seen only 2 cases of HIV associated gangrene out of the 1311 cases HIV infected patients. We describe our experience of one of our patients of HIV infection with gangrene.

\subsection{Case report}

A woman aged 32 years presented to the outpatient department of our institute with complaints of pain and blackish discoloration of left foot since 1 month. She did not have diabetes mellitus or hypertension. She was non smoker and non alcoholic. There was no history of coronary artery disease or cerebrovascular diseases.

On examination she was emaciated. Pallor and oral thrush were noted. There was no lymphadenopathy. Vitals were normal. Cardiovascular, abdomen and respiratory systems were normal. Left foot was dry, gangrenous with blackish discoloration (Figure 2). Dorsalis pedis, posterior tibial pulses were not palpable. Sensations decreased on the foot. Hemoglobin was $10 \mathrm{gm} / \mathrm{dL}$, Total leucocyte count was 10,000/cmm with neutrophils $66 \%$, lymphocytes $28 \%$, Eosinophils $4 \%$, and monocytes $2 \%$. Platelets were normal. Peripheral smear examination showed normocytic, normochromic anemia. Erythrocyte sedimentation rate was $20 \mathrm{~mm}$ at $1^{\text {st }}$ hour. Liver function tests and renal function tests were normal. Lipid profile was normal. Anti nuclear factor (ANF), perinuclear and cytoplasmic anti neutrophil cytoplasmic antibodies ( $\mathrm{P}$ and C-ANCA) were negative. Australian Antigen and HCV antibodies were negative.

She was evaluated and was found to have HIV-1 infection. CD4 count was 106 cells/ $\mu \mathrm{L}$. Patient's spouse was tested reactive for HIV 1 and was receiving HAART. She had one male child who was 8 years old and had been tested non reactive for HIV infection. She was started on highly active antiretroviral therapy (HAART) and low dose prednisolone. Pain reduced and a line of demarcation developed.

\section{Discussion}

HIV-associated vascular disease is a specific disease entity which differs from atherosclerotic disease in various aspects. HIV positive patients with vasculopathy are younger with an average age of 40 years in comparison to 55 years in patients with atherosclerotic disease (Botes \& Van Marle, 2007). There is also a lower incidence of the typical risk factors for atherosclerosis like smoking, hypertension, hypercholesterolemia and diabetes mellitus in these patients with HIV with peripheral vascular disease. CD4 T-cell 


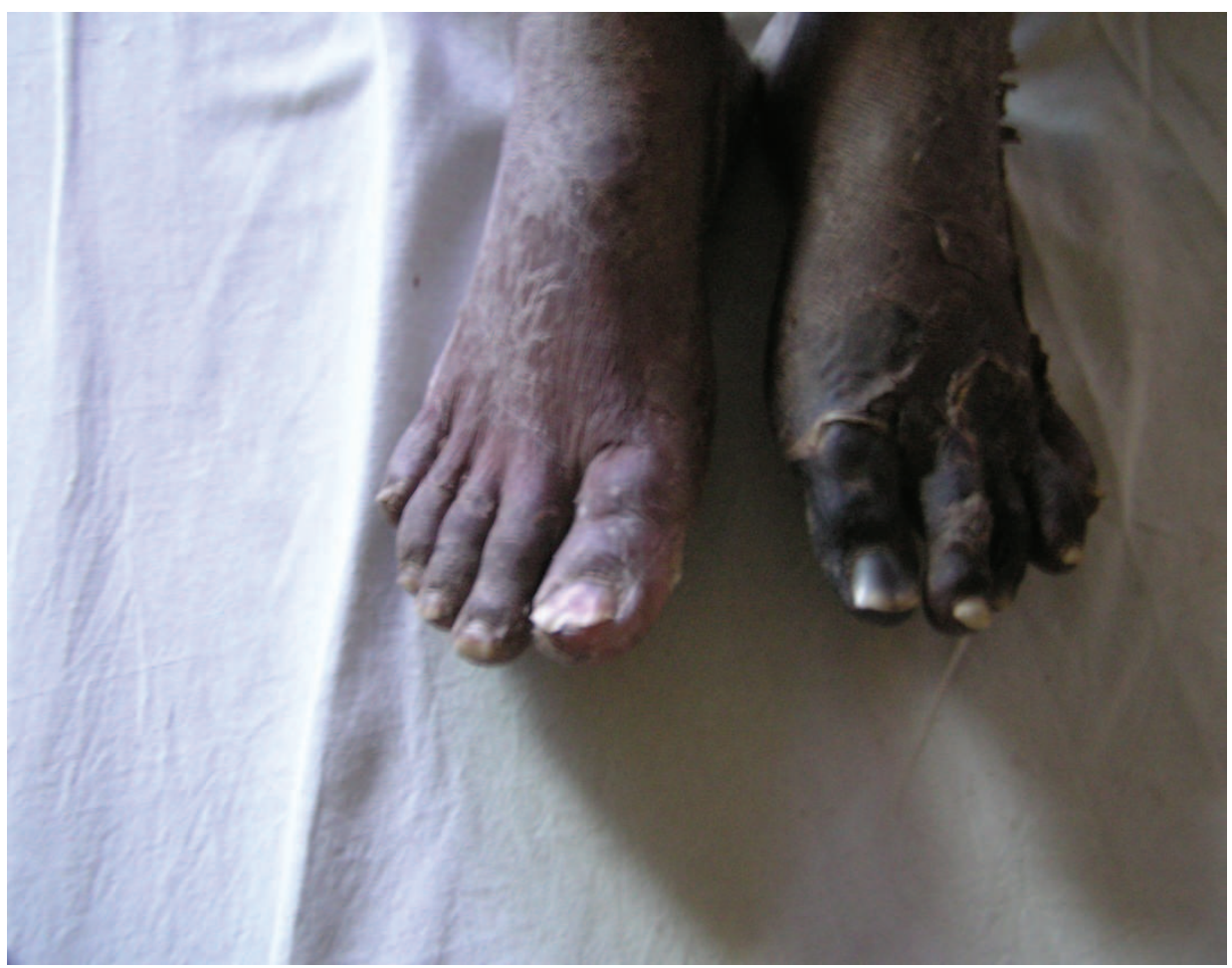

Fig. 1. Gangrene involving left foot in a woman aged 32 years with HIV infection

count $<200$ cells $/ \mu$ l was found as significant predictor of PAD in HIV (Periard et al., 2008). Literature suggests that the incidence of symptomatic vasculitis is in the region of $0.4 \%$ to $1 \%$ of HIV-infected patients (Kaye, 1996; Kakrani et al., 2003). However, we have seen only 2 cases of HIV associated gangrene over last 10 years. The reason for the low incidence in our experience is possibly due to the free antiretroviral treatment (ART) at the government funded ART centres in our state. Another reason for the low incidence of peripheral vascular disease is because we did not screen for any subclinical vascular disease in our patients. As observed in our cases CD4 counts in patients with HIV vasculopathy are below normal in more than $90 \%$ of patients and the CD4:CD8 ratio is usually reversed, indicative of advanced immunosuppression (Mulaudzi et al., 2005).

\subsection{Etiology of gangrene in HIV}

Infections, occlusive disease due to a hypercoagulable state, vasculitis are some of the mechanisms suggested for gangrene of the extremities in HIV. There have been reported findings of anti-phospholipid antibody syndrome, deficiencies of free protein S, protein C and anti-thrombin 3, but these have been sporadic reports. Chronic HIV infection, rather than its pharmacologic treatment, induces alterations of markers of endothelial dysfunction (Torriani et al 2008). However some opine that despite minimizing HIV plasma burden and subsequent associated inflammatory damage, antiretroviral medications may independently contribute to endothelial damage (Gaetano et al., 2003; Chai et al., 2005; Shankar et al., 2005). 
HIV-infected patients tend to develop decreases in high density lipoprotein cholesterol (HDL-c) and low density lipoprotein cholesterol (LDL-c) levels, followed by an increase in plasma triglyceride levels, independent of any exposure to antiretroviral therapy (Grunfeld et al., 1992).

Viral infections have been implicated in the pathogenesis of systemic vasculitis, and many viruses, including HIV, are associated with vasculitis and occasionally gangrene. As in any immunocompromised state, opportunistic infections are likely in patients with HIV infection. Vasculitis and gangrene may be a manifestation of these opportunistic infections. Cytomegalovirus (CMV), Herpes zoster virus (HZV), toxoplasmosis, pneumocystis, salmonella, and Mycobacterium tuberculosis have all been associated with vasculitis in patients with HIV infection ${ }^{1}$. The two major mechanisms by which infection is thought to induce a vasculitis are direct microbial invasion, with resultant damage of the vessel wall, and immune mediated injury both humoral and cellular (Chetty, 2001).

Another mechanism for development of vasculitis in patients after start of antiretroviral therapy (ART) is immune-reconstitution inflammatory syndrome (IRIS). IRIS occurs within a few weeks to months after the start of HAART; patients most often present with clinical deterioration while the number of CD4 lymphocytes is increasing and the HIV viral load decreasing. IRIS could be implicated in the pathogenesis of the vascular complications (Venkataramana et al., 2006).

Various abnormalities predisposing to a hypercoagulable state have been detected in HIV patients, including antiphospholipid antibodies, lupus anticoagulant, increased Von Willebrand factor (vWF), deficiency in protein C and S, antithrombin and heparin co-factor. Viral-induced endothelial injury causes increased levels of Von Willebrand factor, total antigenic protein S, plasminogen activator inhibitor (PAI-1), endothelial-derived thrombomodulin and other procoagulant products of endothelial cell activation (Saif et al., 2001). Some of the rare causes which contribute to gangrene in HIV include thrombotic thrombocytopenic purpura (de Man et al., 1997).

\subsection{Clinical features}

$\mathrm{HIV}$-associated arterial occlusive disease is recognised as a specific clinical entity. Median age of patients is between 30 - 40 years (Mulaudzi et al., 2005). Male preponderance has been observed in HIV associated vasculopathy (Mulaudzi et al., 2005). The vessels reported to be commonly affected are arteries of muscles and digits. In HIV related occlusive vascular disease two patterns of presentation have been reported (Robbs \& Paruk, 2010). In the first type, there is no antecedent claudication and patients present with acute thrombosis. In this type angiographically, proximal vessels appear normal but there is segmental occlusion with poor distal runoff. The second group with occlusive disease appears to have premature atherosclerotic disease. The majority of the patients present with critical ischaemia with rest pain or gangrene.

In most patients the disease is confined to one limb, for reasons that are obscure. However there are case reports describing gangrene involving upper limbs in children with HIV (Despina et al., 2008). Cases of polyarteritis nodosa (PAN) like systemic necrotizing vasculitis in HIV infected individuals, with digital ischaemia are reported (Kakrani et al., 2003). As vasculopathies occur during the later stages of the HIV disease process and are a marker for advanced disease, a thorough search for opportunistic infections should be made in these patients. There are reports of increase in prevalence of Fournier's gangrene in patients with HIV in their surgical ward during post HIV era (Elem\& Ranjan, 1995). There 
are case reports from India on gangrene involving unusual sites like breast in HIV patients (Venkatramani et al., 2009.)

\subsection{Diagnosis}

HIV associated gangrene may be associated with a known pathogen or trigger, or may occur in the absence of an obvious identifiable agent. To establish an opportunistic infection associated with the vascular pathology either a serological test, staining of smears on light microscopy, cultures, immunohistochemistry testing, and in situ hybridisation tests or viral markers may be done as are relevant based on the clinical presentation.

Work up for autoimmune diseases and procoagulant states- antinuclear antibodies, antiphospholipd antibodies, protein C, S and anti- thrombin III need to be planned in patients with HIV with gangrene. Patients with peripheral arterial disease can be easily and reliably identified by ankle brachial index (ABI) testing, and they presumably are at increased cardiovascular risk, assuming that ABI mortality correlations from the general population can be extrapolated to HIV-infected persons (Periard et al., 2008).

Doppler study of arterial and venous system is essential in all patients with ischemic changes. There is a pathognomonic sign with hypoechoic spotting within the arterial wall best described as string of pearls sign (Woolgar et al., 2002).

Diagnostic angiography in known HIV-positive patients with vasculopathy requires awareness of the manifestations of the disease (Scholtz, 2004). The uncommon sites and multiplicity of vascular involvement usually imply that additional images, with an increased volume of contrast media, will be required. Owing to the increased risk of thrombosis, care should be taken to adequately heparinize these patients during diagnostic or interventional procedures. In a series on vascular involvement in HIV patients, it was noted that the majority of the patients presented with occlusive disease, followed by aneurysms, usually atypical in location, multiple, clustered and with a predilection for the extracranial carotid arteries followed by the thoracoabdominal aorta and superficial femoral arteries(Sholtz, 2004). Angiographic appearances vary in the two types of HIV related occlusive vascular disease. In the acute thrombosis group, the angiographic picture is one in which the proximal vessels are normal, accompanied by aggressive peripheral thrombotic occlusion and very poor distal runoff.

A careful clinicopathological correlation is particularly important in skin biopsies showing a vasculitic reaction. There are five patterns of vasculitis described in HIV i.e. lymphocytic vasculitis(LyV), leucocytoclastic vasculitis(LCV) of small dermal vessels, neutrophilic vasculitis with vascular thrombosis and intradermal suppuration, vasculitis with palisaded neutrophilic neutrophilic and granulomatous dermatitis and large vessel vasculitis affecting subcutaneous vessels (Grayson, 2008).

The last three patterns usually infer systemic involvement. A neutrophilic (leucocytoclastic) vasculopathic reaction in the HIV positive individual may have many potential causes, including infection with HIV per se. Other viral causes of hypersensitivity vasculitis include $\mathrm{CMV}$, hepatitis B virus, and Epstein-Barr virus. The dermal vessels in skin biopsies from cases of HSV or varicella zoster virus (VZV) infection frequently exhibit LCV. Recurrent varicella may even manifest with vasculitis in the absence of epidermal involvement. Drugs that may precipitate LCV include certain HAART agents, penicillin and the sulphonamides. The presence of acute LCV in association with vascular occlusion may signify either HIVassociated mixed cryoglobulinaemia (with small vessel occlusion by cryoglobulin precipitates) 
or septic vasculitis (with dermal vascular occlusion by infected microthrombi). The latter may be associated with intradermal abscess formation and/or cutaneous infarction (Carlson, 2005).

\subsection{Management}

HIV-associated vasculopathy is not cited in the World Health Organization (WHO) clinical staging system. As HIV associated vasculopathy and gangrene are pointers to an advanced stage of the disease it would be logical to offer antiretroviral therapy irrespective of the CD4 level. Recent publications have shown that HIV itself as a risk factor for peripheral artery disease and strongly recommended NRTI and NNRTI containing regimens (Ye, 2010). As a class, the protease inhibitors appear to have the greatest negative impact on total cholesterol and triglyceride levels; however, even within this class, certain agents e.g., atazanivir and darunavir do not have an adverse effect on lipids.

The treatment in patients with acute thrombosis type of occlusive disease depends on the clinical presentation. In those patients wherein the limb cannot be salvaged primary amputation is done. Where the limb is salvageable treatment options include endovascular procedures like thrombectomy and thrombolysis or bypass procedures. However, the limb salvage rate has been in the region of $27 \%$ (Mulaudzi et al., 2005). This is thought to be due to the fact that it is mainly a vasculitic process with superimposed thrombosis, and removing the thrombus does not, in effect, solve the problem, which has a very high rethrombosis rate ${ }^{3}$.

Patients with HIV infection with widespread ischemic necrosis and gangrene may require treatment with corticosteroids (in the event of possible vasculitis), thrombolytic agents (for the thrombotic component), or both, unless there are contraindications to either (Roh \& Gertner, 1997).

In those with chronic occlusive type of disease, in almost half of the patients, there may not be a possibility of reconstruction due to poor runoff or the limb may be beyond salvage. In others standard bypass procedures can be performed and only recently have endovascular procedures been attempted. In this group, the results are marginally better than in the patients with acute thrombosis type of occlusive disease. (Robbs \& Paruk, 2010).

Patients should be optimized as per standard practice prior to surgical or endovascular intervention. Vascular surgical principles should be adhered to when managing patients with HIV-associated occlusive vasculopathy and management should be individualized. Various authors have identified a CD4 T-cell count of less than 200 cells/ $\mu \mathrm{l}$ is an important risk factor for postoperative complications (Lin et al., 2004; Albaran, et al., 1998). A significant complication in all patients in whom surgery is attempted has been the high rate of superficial wound sepsis and graft sepsis. Some centers with vast experience with surgical procedures for occlusive vascular disease in HIV have reported a perioperative mortality of $6.95 \%$ (Van Marle et al., 2009). Primary amputation is usually done for very advanced arterial disease.

\section{Conclusions}

One of the unforeseen consequences of untreated long standing infection with HIV is the appearance of various rheumatic syndromes. Clinicians encountering a patient with gangrene should consider HIV as an important cause and screen for presence of HIV antibodies. Early detection of the HIV infection and appropriate and timely start of HAART can possibly prevent vascular complications. In every patient, workup for both traditional 
and specific risk factors including opportunistic infections and prothrombotic states should be done. Appropriate treatment for the ischemic limb as well as treatment of opportunistic infections and HAART when indicated may significantly improve the outcomes. Screening for subclinical vascular disease in asymptomatic patients with simple measures like ankle brachial index and appropriate timely treatment will go a long way in preventing the development of gangrene.

\section{Acknowledgements}

I sincerely thank my husband Dr. P. Narasingarao, Cardiac Surgeon at Kamineni Hospital, King Koti for the support and guidance during the preparation of the manuscript.

\section{References}

Albaran, RG.; Webber, J., \& Steffes, CP. (1998). CD4 cell counts as a prognostic factor of major abdominal surgery in patients infected with the human immunodeficiency virus. Arch Surg, Vol. 133, pp. 626-631.

Botes, K. \& Van Marle, J. (2007). Surgical Intervention for HIV Related Vascular Disease. Eur J Vasc Endovasc Surg, Vol. 34, pp. 390-396.

Carlson, JA.; Ng, BT. \& Chen, K-R. (2005). Cutaneous vasculitis update: diagnostic criteria, classification, epidemiology, etiology, pathogenesis, evaluation and prognosis. Am J Dermatopathol, Vol. 27, pp. 504-528.

Chai, H.; Yang, H.; Yan, S, et al. (2005). Effects of 5 HIV protease inhibitors on vasomotor function and superoxide anion production in porcine coronary arteries. J Acquir Immune Defic Syndr, Vol. 40, p. 12.

Chetty, R. (2001). Vasculitides associated with HIV infection. J Clin Pathol, Vol. 54, pp. 275-278.

Daniel, Periard.; Matthias, Cavassini; Patrick Taffe, et al. (2008). High Prevalence of Peripheral Arterial Disease in HIV-Infected Persons. Clinical Infectious Diseases, Vol. 46, pp. 761-767.

de Gaetano, Donati, K.; Rabagliati, R.; Tumbarello, M., et al. (2003). Increased soluble markers of endothelial dysfunction in HIV-positive patients under highly active antiretroviral therapy. AIDS, Vol. 17, p. 765.

de Man, AM.; Smulders, YM.; Roozendaal, KJ., et al. (1997). HIV-related thrombotic thrombocytopenic purpura: report of 2 cases and a review of the literature. Neth J Med, Vol. 51, pp. 103-109.

Despina, Demopoulos; Hendson, W.; Technau, K., et al. (2009). Vasculopathy in HIVinfected children - a case series. S Afr J CH, Vol. 3, pp. 27-30.

Elem, B.; \& Ranjan, P. (1995). Impact of Immunodeficiency virus (HIV) on Fournier's gangrene: observations in Zambia. Ann R Coll Surg Engl, Vol. 77, pp. 283-286.

Grayson, W. (2008). The HIV-positive skin biopsy. J Clin Pathol, Vol. 61, pp. 802-817.

Grunfeld, C.; Pang, M.; Doerrler, W. \& Shigenaga, JK. (1992) Lipids, lipoproteins, triglyceride clearance and cytokines in human immunodeficiency virus infection and the acquired immunodeficiency syndrome. J Clin Endocrinol Metab, Vol. 74, p. 1045.

Joshi, VV.; Pawel, B.; Connor, E., et al. (1987). Arteriopathy in children with acquired immunodeficiency syndrome. Pediatr Pathol, Vol. 7, pp. 261-275.

Kakrani, AL.; Anita Basavraj, R; Madraki. (2003). Vasculitis with digital gangrene in a patient with HIV Infection. J Assoc Physicians India, Vol. 51, pp.299-301. 
Kaye, B. (1996). Rheumatologic manifestations of HIV infections. Clin Rev Allergy Immunol, Vol. 14, pp. 385-416.

Leonie Scholtz. (2004). Vascular Manifestations of HIV/AIDS. Cardiovasc Intervent Radiol, Vol. 27, pp. 422-426.

Lin, PH.; Bush, RL.; Yao, Q, et al. (2004). Abdominal aortic surgery in patients with human immunodeficiency virus infection. Am J Surg, Vol. 188, pp. 690-697.

Mulaudzi, TV.; Robbs, JV.; Pillay, W, et al. (2005). Thrombectomy in HIV related peripheral arterial thrombosis: a preliminary report. Eur J Vasc Endovasc Surg, Vol. 30, No.1, pp. 102-106.

Nair, R.; Abdool-Carrim, ATO.; Chetty R., et al. (1999). Arterial aneurysm in patients infected with human immunodeficiency virus: a distinct clinicopathology entity? J Vasc Surg, Vol. 29, pp. 600-607.

Nair, R.; Chetty, R. ; Woolgar, J., et al. (2001). Spontaneous arteriovenous fistula resulting from HIV arteritis. J Vasc Surg, Vol. 3, No.1, pp. 186-187.

Nair, R.; Robbs, JV.; Chetty, R., et al. (2000). Occlusive arterial disease in HIV-infected patients: a preliminary report. Eur J Vasc Endovasc Surg, Vol. 20, pp. 353-357.

Narasinga Rao Pantula, \& Malladi Venkata Surya Subbalaxmi. (2009). Repair of aortic dissection in a patient with advanced AIDS. Ind J Thorac Cardiovasc Surg, Vol. 25, pp. 65-67.

Periard, D.; Cavassini, M.; Taffé, P., et al. (2008). High prevalence of peripheral arterial disease in HIV-infected persons. HIV/AIDS CID, Vol. 46, pp. 761-767.

Robbs, JV.;Paruk,N.; (2010) Management of HIV Vasculopathy -A South African Experience. Eur J Vasc Endovasc Surg Vol. 39 pp. S25eS31.

Roh, SS., \& Gertner, E. (1997). Digital necrosis in acquired immune deficiency syndrome vasculopathy treated with recombinant tissue plasminogen activator. J Rheumatol, Vol. 24, pp. 2258-2261.

Saif, MW.; Bona, R.; \& Greenberg, B. (2001). AIDS and thrombosis: Retrospective study of 131 HIV-infected patients. AIDS Patient Care and STDs, Vol. 15, pp. 311-320.

Shankar, SS.; Dube, MP.; Gorski, JC., et al. (2005). Indinavir impairs endothelial function in healthy HIV-negative men. Am Heart J, Vol. 150, p. 933.

Torriani, FJ.; Komarow, L.; Parker, RA., et al. (2008). Endothelial function in human immunodeficiency virus-infected antiretroviral-naive subjects before and after starting potent antiretroviral therapy: The ACTG (AIDS Clinical Trials Group) Study 5152s. J Am Coll Cardiol, Vol. 52, p. 569.

Uppal, SS., \& Achutan, K. (1997). Impact of HIV infection on rheumatic diseases. J Assoc Physicians India, Vol. 45, pp. 387-391.

Van Marle, J.; Mistry, PP., \& Botes, K. (2009). Vascular disease in HIV/AIDS.SAJS, Vol. 47, pp. 37-42.

Venkataramana, A.; Pardo, CA., McArthur, JC, et al. (2006). Immune reconstitution inflammatory syndrome in CNS of HIV- infected patients. Neurology, Vol. 67, pp. 383-388.

Venkatramani, V.; Pillai, S.; Marathe, S; et al. (2009). Breast gangrene in an HIV-positive patient AnnR Coll Surg Engl Vol. 91, pp.1-2.

Woolgar, JD.; Ray, R.; Maharaj, K., et al. (2002). Colour Doppler and grey scale ultrasound features of HIV-related vascular aneurysm. Br J Radiol, Vol. 75, pp. 884-888.

Yikong, Ye; Yong Zeng; Xiaomeng Li, et al. (2010). HIV infection: An independent risk factor of peripheral artery disease. J Acquir Immune Defic Syndr, Vol. 53, pp. 276-278. 


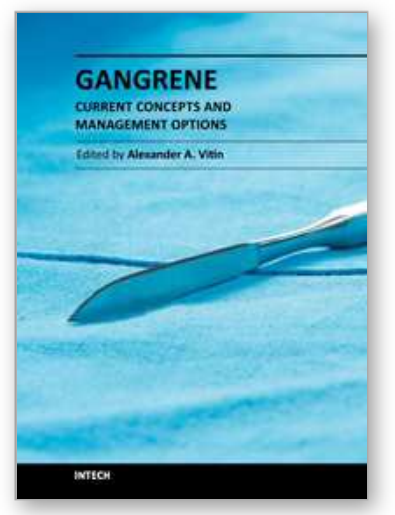

\author{
Gangrene - Current Concepts and Management Options \\ Edited by Dr. Alexander Vitin
}

ISBN 978-953-307-386-6

Hard cover, 178 pages

Publisher InTech

Published online 29, August, 2011

Published in print edition August, 2011

Gangrene is the term used to describe the necrosis or death of soft tissue due to obstructed circulation, usually followed by decomposition and putrefaction, a serious, potentially fatal complication. The presented book discusses different aspects of this condition, such as etiology, predisposing factors, demography, pathologic anatomy and mechanisms of development, molecular biology, immunology, microbiology and more. A variety of management strategies, including pharmacological treatment options, surgical and non-surgical solutions and auxiliary methods, are also extensively discussed in the bookâ $€^{\mathrm{TM}} \mathrm{s}$ chapters. The purpose of the book is not only to provide a reader with an updated information on the discussed problem, but also to give an opportunity for expert opinions exchange and experience sharing. The book contains a collection of 13 articles, contributed by experts, who have conducted a research in the selected area, and also possesses a vast experience in practical management of gangrene and necrosis of different locations.

\title{
How to reference
}

In order to correctly reference this scholarly work, feel free to copy and paste the following:

Malladi VSS, Abkari S and Srinivasan VR (2011). Gangrene Associated with Human Immunodeficiency Virus (HIV), Gangrene - Current Concepts and Management Options, Dr. Alexander Vitin (Ed.), ISBN: 978-953-307386-6, InTech, Available from: http://www.intechopen.com/books/gangrene-current-concepts-andmanagement-options/gangrene-associated-with-human-immunodeficiency-virus-hiv-

\section{INTECH}

open science | open minds

\author{
InTech Europe \\ University Campus STeP Ri \\ Slavka Krautzeka 83/A \\ 51000 Rijeka, Croatia \\ Phone: +385 (51) 770447 \\ Fax: +385 (51) 686166 \\ www.intechopen.com
}

\author{
InTech China \\ Unit 405, Office Block, Hotel Equatorial Shanghai \\ No.65, Yan An Road (West), Shanghai, 200040, China \\ 中国上海市延安西路65号上海国际贵都大饭店办公楼 405 单元 \\ Phone: +86-21-62489820 \\ Fax: $+86-21-62489821$
}


(C) 2011 The Author(s). Licensee IntechOpen. This chapter is distributed under the terms of the Creative Commons Attribution-NonCommercialShareAlike-3.0 License, which permits use, distribution and reproduction for non-commercial purposes, provided the original is properly cited and derivative works building on this content are distributed under the same license. 